\title{
AVALIAÇÃO DO ENSINO E APRENDIZAGEM
}

\section{ARTIGO DE REVISÃO}

PINTO, Jacyguara Costa ${ }^{1}$

RODRIGUES, Helton Barbosa ${ }^{2}$

SILVA, Vanessa de Souza da ${ }^{3}$

PINTO, Jacyguara Costa. RODRIGUES, Helton Barbosa. SILVA, Vanessa de Souza da. Avaliação do ensino e aprendizagem. Revista Científica Multidisciplinar Núcleo do Conhecimento. Ano 04, Ed. 11, Vol. 03, pp. 81-90. Novembro de 2019. ISSN: 24480959,

acesso: https://www.nucleodoconhecimento.com.br/educacao/avaliacao-do-ensino

\section{RESUMO}

O artigo apresenta estudos sobre os novos desafios postos á educação, sendo imprescindível pensar no modelo de avaliação utilizado pelos docentes atualmente. Por isso, buscou-se analisar os processos de planejamento avaliativo realizado nas séries iniciais do Ensino Fundamental. Os resultados foram obtidos através do uso do método de pesquisa bibliográfica de natureza descritiva e abordagem qualitativa,

${ }^{1}$ Doutor em Ciência da Educação, Mestre em Ciência da Educação, Especialista Lato Sensu em Docência de Ensino Superior, Especialista Lato Sensu Em História cultura, Literatura Africana, afro-brasileira, licenciado e Bacharel em História.

2 Mestre em Ciência da Educação, Licenciatura Plena e Bacharel em Geografia, Especialista Lato Sensu em Gestão Ambiental, professor da Rede pública estadual, atualmente exercendo suas funções de docente na educação básica no Sistema Organizacional ensino Modular do Estado do Amapá.

${ }^{3}$ Mestrando em Ciência da Educação, Especialista em ensino especial, Licenciada plena pedagogia, professora da rede pública Estadual e Municipal no Estado do Amapá. 
realizando-se a análise de conteúdos de livros e artigos científicos que permitiram conectar os estudos e as perspectivas empíricas do pesquisador, norteando a construção dos resultados em três seções, as quais foram descritas deste ponto em diante. No desenvolvimento do artigo foi analisada a avaliação do ensino e aprendizagem, fora descrita a importância da auto avaliação para o educador imparcial; e, foi possível compreender, brevemente, a adoção da avaliação participativa por objetivos na realidade educacional do Ensino Fundamental. Concluiuse, que o problema do artigo foi respondido, o objetivo geral foi atingido e confirmouse a hipótese de que qualquer instrumento utilizado pelos professores e pela escola para realizar a avaliação, configura uma forma de estabelecer níveis de aprendizado, reconhecer os melhores e os piores, e principalmente, adequar o ensino às normas de excelência instaladas pela escola. Medidas padronizadas têm desviado o sentido democrático, crítico, construtivo e criativo da avaliação, impedindo o percurso de uma aprendizagem efetiva.

Palavras chave: Avaliação, competências, desempenho, objetivos, escola.

\section{INTRODUÇÃO}

A Educação em nosso país é bastante complexa, a segregação da sociedade tem esfacelado grupos de pessoas, sendo estas, vítimas das disparidades que são os reflexos da incúria do poder público.

Essas disparidades refletem nas relações existentes na escola. Levando o indivíduo a questionar suas condições, como um ser capaz de construir suas concepções de ser humano, de sociedade e de mundo, na busca de satisfazer suas necessidades em diversas dimensões e ao mesmo tempo legitimar sua identidade perante seus pares.

Diante dos novos desafios postos à educação é imprescindível pensar no modelo de avaliação utilizado pelos docentes atualmente, tendo em vista que o ato de avaliar, qualquer que seja o modelo adotado não é neutro, pois ele traz em seu bojo uma determinada forma de conceber a realidade, o indivíduo e a sociedade, direcionando e condicionando a prática pedagógica existente na sala de aula e na escola. 
Qualquer que seja o instrumento utilizados pelos professores e pela escola para realizar a avaliação, configura de certa, estabelecer níveis de aprendizado, reconhecer os melhores e os piores, e principalmente, adequar o ensino às normas de excelência instaladas pela escola. Medidas padronizadas têm desviado o sentido democrático, crítico, construtivo e criativo da avaliação, impedindo o percurso de uma aprendizagem efetiva. Partindo desses pressupostos é que se inicia a investigação com a seguinte problemática: Que relação existe entre as ações de planejamento da avaliação escolar com a melhoria do rendimento educacional do aluno?

Dessa forma, justifica-se a pretensão de refletir sobre os processos que envolvem o planejamento avaliativo escolar como um momento de aprendizagem, um meio em que o professor utiliza para mediar o conhecimento e não um fim, visto que, a avaliação não se limita apenas a determinação de notas, mas acompanha o caminho que o aluno percorre, descobre suas dificuldades e altera os rumos, se necessário.

Dessa forma, o objetivo do artigo foi analisar os processos de planejamento avaliativo realizado nas séries iniciais do Ensino Fundamental. Especificamente, pretende-se analisar a avaliação do ensino e aprendizagem; descrever a importância da auto avaliação para o educador imparcial; e, compreender a adoção da avaliação participativa por objetivos na realidade educacional do Ensino Fundamental.

Os resultados foram obtidos através do uso do método de pesquisa bibliográfica de natureza descritiva e abordagem qualitativa, realizando-se a análise de conteúdos de livros e artigos científicos que permitiram conectar os estudos e as perspectivas empíricas do pesquisador, norteando a construção dos resultados em três seções, as quais foram descritas deste ponto em diante.

\section{ACERCA DA AVALIAÇÃO DO ENSINO E APRENDIZAGEM}

De acordo com a época e o modelo de sociedade, a avaliação tem sua trajetória desde os tempos mais remotos. Alguns autores como Soeiro e Aveline (1982) expuseram como origem dos métodos avaliativos, as atividades que os primeiros conglomerados humanos realizavam para, através de rituais, tornar o jovem indígena pronto para ser 
um adulto indígena. Para esses autores, tais práticas remontam a 360.a.C considerado como sistema de critérios usados pelos chineses e gregos para habilitar indivíduos para determinado trabalho, possibilitava todos os cidadãos de alcançar cargos de prestígios e poder.

Desde os primórdios já havia formas de avaliar, ato este utilizado pelos chineses e gregos no mercado de trabalho, isto acontecia de maneira inconsciente, imposta pelo modelo de cultura da sociedade, com objetivos de preparar e selecionar os melhores para exercer os cargos de prestígios e poder. Esse modelo de avaliação, também era usado na China, nos idos de 2200 a.C. (SOEIRO; AVELINE, 1982).

$\mathrm{Na}$ Grécia, Sócrates sugeria uma auto avaliação, "conhece-te a ti mesmo" como forma para chegar a verdade. Assim, esse pensamento filosófico se tornou uma forma de exame, ou seja, a autoavaliação, uma ação de extrema importância, atualmente, para a eficácia do processo de ensino-aprendizagem.

Para dar maior ênfase à trajetória da avaliação Despresbiteris (1999, p. 113) relata que em "[...] 2005 a.C. o Imperador chinês Shum examinava seus oficiais a cada três anos com o objetivo de promover ou demitir, principalmente para garantir homens capacitados em defesa do estado". Outro importante exemplo de como a avaliação era desenvolvida, consta nas obras de Marx que "[...] o exame não é outra coisa senão o batismo burocrático de conhecimento sagrado" (apud GARCIA, 2001, p. 29).

Sendo assim, o exame é enfatizado como burocracia, ou seja, a parte escrita, em que se relata somente o que convém aos aplicadores, neste caso visa-se a documentação e não o desenvolvimento intelectual utilizando o que é mundano para mudanças e transformações ao conhecimento sagrado.

Ainda no século XIII, Kraemer (2005) expõe a utilização de exame como forma de avaliação através da disciplina organizada dos exames e do sistema de atribuição de notas, dando origem a uma ciência chamada Docimologia. Explica ainda que no sentido etimológico a avaliação vem do latim $a+$ valere possuindo como significado atribuição de valor e mérito ao objetivo de estudo. A conceituação utilizada em vários 
países já citados tem como objetivo selecionar pessoas para desempenhar diversas funções no mercado de trabalho.

Com as transformações provenientes da era tecnológica e da industrialização, a partir do século XX, a pesquisa e a avaliação sofreram grandes influências das ciências, foram criados inúmeros procedimentos e teorias utilizados nos dias de hoje, como por exemplo, o Survey $y^{[4]}$ e outros instrumentos: objetivos padronizados e provas escritas.

Vianna (2005) salienta que os trinta primeiros anos da vida social norte-americana no século XX sofreu a influência de três elementos desenvolvidos em princípio, para o gerenciamento industrial: sistematização, padronização e eficiência, que acabaram por afetar a totalidade da sociedade, inclusive na área educacional. Dessa forma, havia uma grande preocupação com o mercado de trabalho, a eficiência era a grande meta e, por consequência, desenvolve técnicas para identificar onde os alunos não estavam conseguindo apreender o conhecimento ministrado na sala de aula.

Nos anos 1970, a avaliação acabou criando um paradigma positivista, o qual deveria ser rompido com a construção de novas formas de avaliação, aplicando-se as novidades que estavam em voga no continente norte-americano. Assim foram desenvolvidos procedimentos de comparação do rendimento dos alunos com testes e a composição de novos planos educacionais incluindo a avaliação como processo de mensuração desse rendimento nas disciplinas. Para Prado de Sousa (1998), foi a partir dos anos 1980 que a avaliação educacional passou a ter uma relevância maior no contexto escolar. Foi quando a Sociologia passou a contribuir com pesquisas e estudos relevantes sobre o funcionamento interno da escola.

O conceito de aprendizagem como um objeto de avaliação, constitui outro pilar na defesa de uma concepção de avaliação educacional. Aprendizagem humana não se limita à aquisição de conhecimentos, habilidades, normas de comportamento, "asséptica" de valores e sentido pessoal. A utilização do conceito de aprendizagem para descrever processos e aquisições cognitivas, excluindo "afetiva" e "conativo" é inconsistente porque distorce a realidade que se destina afetiva e avaliativa desconhecido dimensão do conhecimento. Toda a ação cognitiva tem valor, 
conhecimento, habilidade, forma de comportamento carrega um sentido pessoal, é um assunto que aprende. A avaliação exige ter o modelo de objeto a partir de uma perspectiva integral, holística e multifacetada que destaca a complexidade e riqueza de aprendizagem. Eles argumentam que a necessidade de avaliação de ensino ou de formação (GIBBS, 2003).

\section{A IMPORTÂNCIA DA AUTO AVALIAÇÃO PARA O EDUCADOR IMPARCIAL}

A auto avaliação tem sido considerada uma estratégia muito eficaz por adotar conceitos democráticos no processo de gestão escolar, tornando cidadãos, gestores, professores e toda a comunidade escolar participantes do processo de alocação de recursos na educação escolar (CAMILLONI, 1997).

O esquema da auto avaliação consiste em fazer com que os processos internos e externos em que a escola esteja participando possam ter seus resultados mensurados racionalmente e demonstrar a eficiência para a maneira com que os erofeogicos e didáticealizar seus planejamentos pedagógicos e didáticos nas estratégias de ensino em sala de aula, assim, há autoavaliação quando consegue-se identificar pontos fortes (potências) e frágeis (efemérides) nos resultados.

Os problemas dos sujeitos da avaliação é abordar o debate sobre quem deve, pode e é capaz de participar na avaliação. Ele luta e defende a necessidade e o estudante universitário direito de participar na sua avaliação, o valor educativo e de formação que carrega a si mesmo e os outros sujeitos do processo ensino-aprendizagem. A auto e hetero são facetas necessárias de trabalho individual e em grupo no ensino superior, que reforçam e expressam a relação entre o trabalho do grupo e da responsabilidade individual de cada tributo especial a ele; de modo a contribuir para o desenvolvimento da responsabilidade social da pós-graduação, como um requisito para o ensino superior. É estabelecido como um fim legítimo que reverta avaliador avaliado. 
A auto avaliação acontece por meio de processos que, ao professor, quando realizao e adota-os, carecem conhecimento em relação as informações e critérios que precisa ser avaliado por terem sido realizados por quem os está avaliando, mensurando os próprios resultados e considerando se tais resultados próprios foram satisfatórios para o sucesso do processo ensino aprendizagem. Nesse caso, os professores aplicam testes auto avaliativos sempre que cursos, palestras, treinamentos e aconselhamentos estão sendo ministrados em sala de aula e em outros espaços das escolas.

A avaliação educacional, desde a sua origem, já traz em seu bojo uma complexidade, devido os inúmeros fatores que devem ser considerados ao se avaliar alguém ou algo, sendo importante enfatizar que existe hoje em dia uma consciência da sociedade brasileira a respeito da relevância do processo avaliativo educacional.

Portanto, avaliar é preciso, e continuamente, ainda mais quando a avaliação é encarada como um compromisso formal e uma prática informal. Visto que atualmente a avaliação é entendida como uma ação imprescindível em qualquer momento da vida do ser humano, se opondo com naturalidade a serviço da educação, aproximando experiências de aprendizagens, desenvolvimento humano, melhoria de qualidade de vida, bem-querer, elevação de autoestima e valorização de iniciativas entre as pessoas.

Garantir uma educação para todos está relacionada à mudança de um currículo distante das problemáticas do mundo e dos interesses dos próprios alunos para um currículo capaz de captar o interesse tanto de alunos como de professores, favorecendo a compreensão dos fenômenos naturais, sociais e culturais, como instrumento que predisponha ao questionamento, à aprendizagem na ação, à atitude de enfrentar a incerteza da complexidade, considerando os novos saberes, habilidades e valores.

O educador necessita reavaliar suas práxis e didática procurando desenvolver um conteúdo mais significativo e uma metodologia mais participativa, de tal forma que diminua a necessidade de recorrer à nota como instrumento de coerção. Esta tarefa 
não é fácil no contexto atual, este desempenho do educador tem a ver com o enfrentamento da alienação: trata-se de uma luta de perspectivas, de sentidos para o conhecimento e para a vida.

Nesse contexto, a LDB como norteadora legal das políticas educacionais visa recuperar através da escola pública seu papel na formação da cidadania, estando aberta a todos os alunos, sem discriminação, integrando a diversidade sociocultural e as diferenças individuais contribuindo, assim, para uma socialização integradora. A educação para a cidadania aponta um caminho para fazer frente aos novos problemas, ao mesmo tempo em que permite integrar os valores e temas transversais, em vez de apresentá-los como ações pontuais ou isoladas, sem se restringir à aprendizagem de determinados valores, comportamentos ou atitudes, visto que o cidadão necessita de todo o conjunto de saberes e competências que lhe permitam uma participação ativa na vida pública, sem os quais poderá ser excluído ou ter sua cidadania negada.

Contudo, ainda há muitos desafios por enfrentar para que a educação pública seja condição para a coesão e integração social: mais eficiência em gestão e mais densidade nos conteúdos; diálogo entre conhecimento científico, os sistemas de interpretação do mundo e a sabedoria ancestral dos povos latino-americanos; abrir as escolas para a sociedade e suas necessidades; definição das competências básicas e fundamentais para a formação dos alunos, com criação de sistemas de informação e avaliação; maior reconhecimento social ao magistério, dignificando e profissionalizando os educadores.

\section{USOS DA AVALIAÇÃO PARTICIPATIVA POR OBJETIVOS NO ENSINO BÁSICO BRASILEIRO}

No contexto atual, a avaliação que temos ainda é por vezes confundida com conceitos e notas, e desempenhada para classificar os alunos em aprovados e reprovados. São minorias aqueles docentes que conseguem visualizar e realizar a avaliação no sentido de contribuir com a qualificação do processo educacional. A maioria prefere classificar 
através das notas, pois julgam ser o caminho mais fácil, que assim terão menos trabalho.

Muitas escolas avaliam seus alunos por meio de exames, práticas essas com cunho positivista e tecnicista que não contemplam o aprendizado num todo, agindo de forma classificatória e excludente, pois apesar das notas/conceitos serem um registro necessário, devido ao sistema educacional vigente, elas não podem representar a avaliação em si, distorcendo o processo de ensino-aprendizagem. Nesse tipo de avaliação que classifica, o mais salutar é o produto. Refletindo, uma educação baseada na memorização de conteúdo.

Ao contrário desse tipo de avaliação que dá ênfase na atribuição de notas e classificação, pode-se evidenciar a avaliação qualitativa que se fundamenta num paradigma crítico e visa à melhoria da qualidade do sistema educacional. Considerando que sua ênfase é no processo de superação das dificuldades dos alunos. E é essa a avaliação que se almeja atualmente, frente a tantos desafios que a escola perpassa diariamente.

Atualmente há um consenso quanto aos novos métodos de avaliação que estão sendo implementados no processo ensino aprendizagem da educação básica. Essa novidade na área da Pedagogia tem gerado a participação dos alunos e tem contribuído com informações e opiniões que podem fomentar a transformação dos saberes e do ensino, e culminar com a melhora da qualidade do ensino com a inserção, por exemplo, da avaliação participativa por objetivos, estratégias avaliativas que coincide opiniões e visão pessoal - crítica ou superadoras - das estratégias que os professores têm adotado em sala de aula.

Essa técnica tem sido empregada para identificar resultados tangíveis dos objetivos e planejamentos pedagógicos considerados pelos professores, identificando-se, ainda pontos relativos aos quadros de desempenho (melhora ou piora) dos alunos, bem como, identificar opiniões destes se forem adotadas mudanças nas atuais práticas pedagógicas. Essa prática possui, segundo Kraemer (2005) duas importantes funções, com suas breves descrições realizadas no quadro 1. 
Quadro 1. Classificação das funções da avaliação por objetivos.

\begin{tabular}{|l|l|}
\hline Classificação & Funções e características \\
\hline Função & $\begin{array}{l}\text { Entre suas funçães, salienta-se as opiniões de quem está sendo } \\
\text { avaliado em relação ao manejo das estratégias de ensino de } \\
\text { professores, por exemplo; ou ainda, as perspectivas dos alunos } \\
\text { sobre as causas de baixo rendimento em sala de aula em } \\
\text { determinada disciplina. Essa forma de coletar dados propõe o } \\
\text { uso de pré-testes, sondagens e estratégias (tempestade } \\
\text { cerebral) inovadoras, ousadas e criativas, que visam auxiliar no } \\
\text { diagnóstico do ensino e da adoção da cultura de mudanças nas } \\
\text { estratégias pedagógicas presentes. }\end{array}$ \\
\hline $\begin{array}{l}\text { Função } \\
\text { somatória, } \\
\text { classificatória }\end{array}$ & $\begin{array}{l}\text { Entre suas características principais, salienta-se a adoção de } \\
\text { avaliações que podem classificar e tipificar o entendimento } \\
\text { sobre as provas elaboradas pelos professores, ou então, a } \\
\text { classificação do aluno no fim do ano letivo (aprovado ou } \\
\text { reprovado). Foi a mais aceita nas escolas por garantir } \\
\text { sinteticamente, a construção de percepções sobre a realidade } \\
\text { escolar na sala de aula e no fim de bimestres e semestres. }\end{array}$ \\
\hline
\end{tabular}

Fonte: Kraemer (2005).

Com este enfoque, pode-se inferir que a avaliação do aproveitamento escolar necessita ser praticada como a atribuição de uma qualidade aos resultados da aprendizagem dos educandos, tendo como base seus aspectos essenciais e que como objetivo final, favoreça uma tomada de decisão que direcione o aprendizado e, consequentemente, o desenvolvimento do educando.

Desse modo, a avaliação diagnóstica, configura-se como um momento de compreensão do estágio em que o aluno se encontra da distância em que se refere aos objetivos articulados a serem atingidos à frente. A avaliação diagnóstica também favorece a participação social de todos os alunos como cidadãos, pois deixa de ter o 
caráter conservador e antidemocrático da avaliação classificatória que excluía muitas pessoas da escola.

Nessa premissa, a avaliação diagnóstica tem por objetivo identificar, verificar, investigar as dificuldades e os objetivos alcançados a fim de redimensionar a ação educativa, sendo que a mesma é um ato processual, levando o educador a refletir sobre o resultado de suas pesquisas, construindo novas propostas, metodologias, com vistas a um ensino de qualidade e comprometimento, precisando avaliar de forma contínua o educando, para detectar os vários momentos de seu desenvolvimento, não se restringindo ao julgamento sobre o sucesso ou fracasso dos alunos, compreendendo-a como um conjunto de atuações que tem a função de orientar a intervenção pedagógica, isso acontece continuamente e sistematicamente por meio da interpretação qualitativa do conhecimento construído pelo educando.

O professor irá utilizar a avaliação como um instrumento que lhe permita questionar constantemente suas propostas no processo de ensino - aprendizagem possibilitando ao educador o redirecionamento de sua prática.

\section{CONCLUSÃO}

Considera-se que o problema do artigo foi respondido, o objetivo geral foi atingido e confirmou-se a hipótese de que qualquer instrumento utilizado pelos professores e pela escola para realizar a avaliação, configura de certa, estabelecer níveis de aprendizado, reconhecer os melhores e os piores, e principalmente, adequar o ensino às normas de excelência instaladas pela escola. Medidas padronizadas têm desviado o sentido democrático, crítico, construtivo e criativo da avaliação, impedindo o percurso de uma aprendizagem efetiva.

Os objetivos também foram atingidos. Em relação ao objetivo de analisar a avaliação do ensino e aprendizagem, os autores analisados expuseram a origem dos métodos avaliativos e seus usos pelos chineses e gregos no mercado de trabalho. A marca do século XIII foram a organização dos exames avaliativos com atribuição de notas, dando origem a uma ciência chamada Docimologia. Hoje, foram desenvolvidos 
procedimentos de comparação do rendimento dos alunos com testes e a composição de novos planos educacionais incluindo a avaliação como processo de mensuração desse rendimento nas disciplinas.

Em relação ao segundo objetivo específico, que propôs analisar a importância da auto avaliação para o educador imparcial, constatou-se nos estudos selecionados que o esquema da auto avaliação consiste em fazer com que os processos internos e externos em que a escola esteja participando possam ter seus resultados mensurados racionalmente e demonstrar a eficiência para a maneira com que os seus planejamentos pedagógicos e didáticos tem gerado resultados satisfatórios nas estratégias de ensino em sala de aula, assim, há autoavaliação quando consegue-se identificar pontos fortes (potências) e frágeis (efemérides) nos resultados.

Por fim, o terceiro objetivo específico foi alcançado, demonstrando que os usos da avaliação participativa por objetivos no ensino básico brasileiro resultam em ir a um caminho contrário ao da avaliação que dá notas e classifica. Sua ênfase é no processo de superação das dificuldades dos alunos. E é essa a avaliação que se almeja atualmente, frente a tantos desafios que a escola perpassa diariamente. Essa técnica tem sido empregada para identificar resultados tangíveis dos objetivos e planejamentos pedagógicos considerados pelos professores, identificando-se, ainda pontos relativos aos quadros de desempenho (melhora ou piora) dos alunos.

\section{REFERÊNCIAS}

CAMILLONI, A. R. W. Los obstáculos epistemológicos em la enseñanza. Barcelona: Gedisa, 1997.

DEPRESBITERIS, Léa. O desafio da avaliação da aprendizagem: dos fundamentos a uma proposta inovadora. $1^{\underline{a}}$ ed. São Paulo: Editora Pedagógica e Universitária, 1999.

GARCIA, Ronaldo Coutinho. Subsídios para organizar avaliações da ação governamental. Planejamento e Políticas Públicas, Brasília, n. 23, p. 7-70, jan. /jun. 2001. 
GIBBS, G. Uso estratégico de la evaluación en el aprendizaje. In: Brown, S.; Glasner, A. Evaluar em la Universidad: problemas y nuevos enfoques. Madrid: Narcea, 2003, pp. 61-70.

KRAEMER, Maria Elisabeth Pereira. A avaliação da aprendizagem como processo construtivo de um novo fazer. Avaliação: Revista da Avaliação da Educação Superior, v. 10, n. 2, 137-147, 2005.

SOEIRO, L \& AVELINE, S. Avaliação Educacional. Porto Alegre: Editora. Sulina, 1982.

VIANNA, Heraldo Marelim. Fundamentos de um Programa de Avaliação Educacional. Brasília: Liber Livro Editora, 2005.

4. Testes normativos usados para avaliar a eficiência da Instituição escolar.

Enviado: Setembro, 2019.

Aprovado: Novembro, 2019. 